\title{
ABSTRACT: IMAGINING THE LAW-TRAINED READER: THE FAULTY DESCRIPTION OF THE AUDIENCE IN LEGAL WRITING TEXTBOOKS.
}

In law schools today, first-year legal writing courses play a crucial role in helping students learn to communicate about the law. Many legal writing teachers approach legal writing education in a practical way, attempting to pass on their own experiences in law practice settings to students. Unfortunately, as other writers have observed, such reliance on personal knowledge about "what lawyers are like" may lead legal writing teachers to oversimplify a complicated matter - the needs and preferences of the audience for legal writing - and may even amount to indoctrination in stereotypes about law practice.

This article offers a closer look than past critiques at the actual depiction of the "law-trained reader" in some popular legal writing textbooks. These texts deliver surprisingly consistent messages about "what lawyers are like," namely, extraordinarily impatient with other people (even in their thinking and reasoning processes); aggressively critical; and conservative and formalistic in outlook. Such over-generalizations about the audience for legal writing seem unlikely to help students improve their legal writing. Worse yet, uncritical presentation of these particular generalizations probably exacerbates student difficulties in reconciling their personal and professional identities during the first year of law school, and may impact female and minority students in a disproportionately negative manner.

Legal writing education should stop inviting law students to imagine the audience for their writing as extraordinarily impatient, aggressive critics, red pens and format guides in hand. Instead, we should develop more careful and reflective methods to assist students in negotiating between their personal and professional voices and grappling with the complex audiences and purposes for their legal writing. 


\section{TABLE OF CONTENTS}

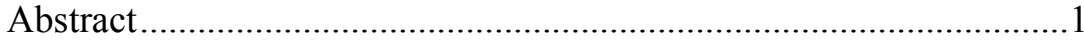

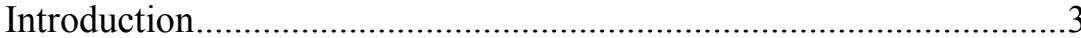

I. The Image of Lawyers in Legal Writing Textbooks:

Impatient, Hyper-Critical Formalists ........................................... 8

A. The first shared trait: extraordinary impatience. ....................9

B. The second shared trait: hypercritical, and

C. The third shared trait: formalism..........................................13

1. Explicit discussion of lawyers' "personal conservatism" and formalism. .....................................13

2. The formula for organizing legal writing: IRAC ............14

3. IRAC as the formula for legal reasoning ........................20

II. What Is the Trouble with Relying on this Image of the Law-Trained Reader?

A. Reliance on generalizations about the audience for legal writing is an ineffective way to help students improve their legal writing

B. Reliance on generalizations about the audience for legal writing creates unnecessary and inequitable pressure to conform.

III. Avoiding Over-Generalizations About the Audience for Legal Writing Improves Legal Writing Education. ...34

Conclusion 


\section{IMAGINING THE LAW-TRAINED READER: ${ }^{1}$ THE FAULTY DESCRIPTION OF THE AUDIENCE IN LEGAL WRITING TEXTBOOKS.}

Learning to write as a lawyer writes means, in a very real sense, becoming a lawyer. When we teach people how to write, we are teaching them not only word choice, organization, or even composing habits; we are also inevitably leading them into the strategies and conventions of a particular discourse and thus offering them membership into that discourse community. ${ }^{2}$

\section{Introduction}

In law schools today, first-year legal writing courses play a crucial role in preparing law students to communicate with the "law-trained reader." Most legal writing teachers approach the task in a practical way. We give our students realistic legal problems to research and analyze. We discuss practical topics such as the relative weight of different legal authorities, the typical structure of legal arguments, and the writing style that (we believe) lawyers prefer. We pass on what we gleaned from practice about the format of common legal documents and the way lawyers analyze legal problems in writing. In short, we try to acquaint students with the law practice settings we ourselves are familiar with, to empower our students to succeed in similar settings.

Unfortunately, relying on our personal knowledge about "what lawyers are like" as the basis for our teaching can lead us into over-generalizing and oversimplifying a complicated matter - the needs and preferences of the audience for legal writing. This article ${ }^{3}$ examines the depiction of the law-trained audience

\footnotetext{
${ }^{1}$ Linda H. Edwards' first-year legal writing textbook gives this label, "law-trained reader," to the members of the audience that law students are writing for. See Linda H. Edwards, Legal WRITING AND ANALYSIS 69 (2003) ("[L]aw-trained readers share certain characteristics. Even in large cities, lawyers and judges live in a legal community that shares certain values, customs and forms expression.")

2 J. Christopher Rideout and Jill J. Ramsfield, Legal Writing: A Revised View, 69 WaSH. L. REV. 35,58 (1994).

${ }^{3}$ I owe thanks to David R. Papke, Rebecca Blemberg, James R. Elkins, and Kathryn Stanchi, for reading and commenting on earlier drafts of this article. Thanks also to the presenters and attendees at the Art of Legal Writing Conference at American University in April 2005, for helpful comments on early versions of this article. And I cannot thank enough my research assistants Elyse Aasen, Caz McChrystal, and David Moore for their research and editing assistance.
} 
in some popular for first-year legal writing and research courses and finds that they lean too heavily on such overgeneralizations. Specifically, these textbooks offer surprisingly consistent messages about lawyers' personalities, namely, that most lawyers are extraordinarily impatient with other people (even in their thinking and reasoning processes); aggressively critical; and conservative and formalistic in outlook. ${ }^{4}$ Such generalizations are an inadequate and inaccurate description of the real "law-trained readers" that students will encounter in practice - individual human beings, working in complicated institutional and social frameworks, and reading for different purposes at different times. ${ }^{5}$ The "law-trained reader" is too diverse and complicated to be captured by such generalizations about the purported shared traits of human beings who have completed law school.

In this article, I argue that legal writing teachers should avoid relying on such over-generalizations, for at least two reasons. First, engaging our students in thinking and discussion about the nature of the audience for whom they are learning to write is more likely to help them learn to write well than relying on overgeneralizations about the audience. ${ }^{6}$ It is better pedagogy to help our students grapple with the complex, varied audiences and purposes for which they will write after law school than to suggest there is some "monolithic" audience of those who have completed law school.

\footnotetext{
${ }^{4}$ See infra Part II.

${ }^{5}$ See Rideout and Ramsfield, supra note 2, at 61 (noting that "[law students and lawyers] are situated in several social settings at once. They are working within the law office and law school communities, whose members are making various and changing demands on the writer. They are usually also working within the larger legal community, whose members have set ethical and practice standards. And they come from different gender, race, and ethnic communities that may generate different learning styles and perspectives."

${ }^{6}$ Similarly, composition teachers and scholars have in recent years questioned the common practice of teaching "audience analysis" as a first step in the "prewriting" stage of the writing process. See Mary Jo Reiff, Teaching Audience Post-Process: Recognizing the Complexity of Audiences in Disciplinary Contexts, 13 WAC. J. 100, 100-01 (2002) (examining writing assignments across the curriculum and across the disciplines, and suggesting that post-process thinking can improve writing education "[b]y challenging the stable, monolithic audience of the classroom.") Of course, the analogy to teaching audience in general composition courses is not quite apt, since legal writing teachers need to help students learn to write for a more particularized audience (and more particular purposes) than general composition teachers. Still, the audience analysis issue in the generalcomposition context has some useful parallels with the issue of how to teach about audience in legal writing courses.

${ }^{7}$ C.f. Reiff, supra note 6, at 100-01.
} 
Second, the particular generalizations found in these textbooks could undermine more than our own teaching - they could undermine law students' abilities to bring their individual perspectives into the legal discourse community. If delivered without question or criticism, teaching students such generalities about the audience for legal writing (stereotypes, really) can become indoctrination, implicitly advice that students must accept and emulate such behavior to succeed in law school and in the law. ${ }^{8}$ Whatever one thinks about the value of impatience, aggressive criticism, and formalism in law practice, such traits are not necessary or even desirable in every area of law practice, and depicting the law-trained audience in such broad strokes is a poor representation of the diverse personalities and approaches that characterize law practice in the United States. ${ }^{9}$ First-year law students are in the midst of a struggle to establish

\footnotetext{
${ }^{8}$ Feminists, for instance, have argued that law teaching in general functions to guide "individual assimilation into hostile, elite, and previously all-male organizations." Lani Guinier ET AL., Becoming Gentlemen: Women's Experiences at One Ivy League Law School, 143 U. PA. L. REV. 1, 6 (1994). In a similar vein, Kathryn Stanchi has discussed how the entire legal writing curriculum, if taught uncritically, helps to achieve the "muting" of outsider voices in the law, at least in part because of the focus on meeting the expectations of the audience of people who have already become lawyers, see Kathryn M. Stanchi, Resistance is Futile: How Legal Writing Pedagogy Contributes to the Law's Marginalization of Outside Voices, 103 DicK. L. REV. 7 (1998), and how legal writing teachers face the decision whether "to ease the students' entry into the [legal] community, [or] to challenge the customs or culture of the community," id. at 22.

Related concerns animate many critiques of legal writing education. See, e.g., Teresa Godwin Phelps, The New Legal Rhetoric, 40 Sw L.J. 1089 (1986); Brook K. Baker, Transcending Legacies of Literacy and Transforming the Traditional Repertoire: Critical Discourse Strategies for Practice, 23 Wm. Mitchell. L. Rev. 491 (1997); Douglas Litowitz, Legal Writing: Its Nature, Limits, and Dangers, 49 MERCER L. ReV. 709 (1998).; Brook K. Baker, Language Acculturation Processes and Resistance to In"doctrine" ation in the Legal Skills Curriculum and Beyond: A Commentary on Mertz's Critical Anthropology of the Socratic, Doctrinal Classroom, 34 J. Marshall L. ReV. 131 (2000). Most recently, Andrea McCardle has reflected on the challenge for clinics, lawyering courses, and legal writing courses to help students "aquir[e] a writing voice that is appropriately professional, without losing a sense of individuality." Andrea McCardle, Teaching Writing in Clinical, Lawyering, and Legal Writing Courses: Negotiating Professional and Personal Voice, 12 CLINICAL L. REV. 501, 502 (2006).

${ }^{9}$ See, e.g., Guinier ET AL., supra note 8, at 84-86. Beyond that, such stereotypes not only blur the diverse backgrounds and personalities of the human beings who make up the legal community, they greatly oversimplify the motivations for lawyers' and judges' preferences and behaviors. Cognitive and social science research shows how such "dispositional" explanations for human behavior, though greatly appealing to many human beings, inadequately account for our actual preferences and choices. See Jon Hanson \& David Yosifon, The Situational Character: A Critical Realist Perspective on the Human Animal, 93 Geo. L. J. 1, 133-35 (2005). "Social science has clearly demonstrated that we are not who we think we are. It is true that we experience ourselves thinking, preferring, acting, and willing, [i.e., as dispositionist] but those comforting perceptions are often illusory, and they obscure the far more significant influence of our unseen interior situation." Id. at
} 
new identities as lawyers, ${ }^{10}$ and we should expect them to listen especially to the messages we send about what lawyers are like, the ways that lawyers think, speak, and behave. ${ }^{11}$ Instructing students about the existence (and implicitly the value) of such generalized personality traits without question or criticism legitimates the traits, even invites students to learn to think and act in the same ways. Unquestioning presentation of such generalizations about the typical "lawtrained reader" might also impact different groups of students differently, building the confidence of students who are already self-identified as impatient, aggressive, and formalistic when they enter law school, and undercutting students who are not, or who cannot or do not want to be. ${ }^{12}$

133. Thus, "[j]udges, being human, understand and portray their individual decisions as both internally coherent and coherent across cases, doctrines, and time" because human beings have an inherent tendency to prefer coherent explanations of their conduct (whether or not their conduct is characterized by coherence). $I d$. at 135 . Similarly, in the legal writing context, a judge's level of impatience with a lawyer's writing in any given instance will relate to various factors such as the particular purpose for which the document is written, the nature of the issues being discussed, what else went on that day, any prior experiences between the particular writer and reader, etc., etc.

${ }^{10}$ See Carrie Yang Costello, Changing Clothes: Gender Inequality and Professional Socialization, N.W.S.A. J.., Summer 2004, at 138; see also James R. Elkins, What Kind of Story is Legal Writing?, 20 LEgAL ST. F. 95 (1996) (discussing Scott Turow's One L and noting that "Turow's narrative hints at how .... [t] he transformation of student into lawyers comes at the cost of a valued sense of self - a Faustian bargain.").

${ }^{11}$ Legal writing courses are not the only courses in the law school in which the teachers present such information about what lawyers are like. Such teaching surely occurs in other practice-like courses, such as clinics, trial practice, and moot court, and probably in many traditional so-called "doctrinal" courses. See McCardle, supra note 8, at 504 (noting that the challenge of helping students "preserve some sense of individual voice and ownership of their writing . . . and negotiate [the] formal structures and idioms" of the legal community is a shared "project for clinical, lawyering, and legal writing teachers."). But legal writing courses are, in most law schools, the courses in which it is most likely that the teachers will directly instruct first-year students about the shared characteristics of the law-trained audience, as they are the first courses in which students are required to role-play the lawyer.

${ }^{12}$ Thus, we might expect teaching students that law-trained readers are, on the whole, impatient, aggressive, and formalistic, seems likely to have disproportionately negative impacts on some students, particularly female students and students from other groups which in the past were excluded from law practice and which remain underrepresented in it, as well as any individual who will not (or cannot) identify with the purported shared characteristics of most lawyers.

In analyzing how the legal communication strategies taught in legal writing courses may work to "mute" the voices of "outsiders" to the legal discourse, Stanchi has discussed the complicated question of whether women and men tend to communicate differently: "the existence and cause of differences in [female] register [that is, linguistic features such as qualifying phrases, softspokenness, etc.] between the powerful and powerless is a matter of intense debate," and at least 
In short, I propose that instead of admonishing students that they must write more clearly and concisely because lawyers share the traits of extraordinary impatience, aggressive criticism, and knee-jerk-formalism, legal writing teachers should engage students in specific, realistic, and critical thinking about the varied and changing audience for legal writing ${ }^{13}$. The legal writing classroom should

three competing theories explaining the perception of such difference: one, the theory that "women use less powerful and effective speech styles because they are socialized to do so, to keep them from positions of power and to avoid offending men"; two, the theory that questions the judgment that the purported women's register is in fact less powerful or effective and instead questions "why certain registers are more valued than others and encourages the valuation of "women's language"; and three, the theory that "it is the identity and position in the social hierarchy of the speaker, not the particular features of speech ... that causes speech to be devalued ... . [s]o [that], for example, a woman who pauses before answering is unsure, a man who pauses is thoughtful." Stanchi, supra note 8 , at $47-49$. There is likely some truth in each of these theories, see id. at 50 ("[p]robably the reality involves a combination, or even synthesis, of these theories").

For discussion of why adopting the characteristics of the stereotype is not necessarily a solution to the problem facing students who perceive themselves, or are perceived by others, not to fit the stereotype, see id. at 51 ("Thus the outsider student's dilemma of whether to change her voice is complicated by the notion that it might make no difference - she still might not be 'heard."'); see also Yang Costello, supra note 10. Yang Costello's research suggest that dissonance between a student's pre-law-school and law-school identities, (that is, perceived dispositions), can have negative personal and professional effects, see generally Yang Costello, impacts which remain regardless of the extent to which disposition actually explains or affects one's experiences.

13 Some composition scholars use the term "situatedness" to describe this concept, that "writing must correspond to specific contexts that naturally vary." See Lee-Ann M. Kastman Breuch, PostProcess "Pedagogy": A Philosophical Exercise, in Cross-Talk In COMP TheORY 115 (VICTOR VillanUeVA, ED. 2003). Though scholars continue to debate whether any "post-process" pedagogy can exist, in view of the "situatedness" and interpretive nature of writing (and perhaps the nature of human communication in general), see id., the "social context" view of legal writing proposed by Rideout and Ramsfield incorporates key concepts of the post-process scholarship into a helpful vision of legal writing pedagogy:

The legal writer cannot write in a vacuum and is not free to pursue writing at leisure. Rather, the situated legal writer must instead learn to write in a new institutional setting, learn a new local practice, and react positively to new and changing circumstances. The revised view suggests that she must build techniques that allow her to respond effectively to the writing demands made of her while at the same time reshaping her writing process. Taken together, these adjustments to a new social and writing context challenge the new lawyer, who is entering a complex world with high stakes. Writing in the practical context requires well-developed techniques, sharpened tools, and cool heads. Law school can offer time to discover and rehearse these techniques so that the new generation of lawyers is well-equipped to communicate effectively within a rapidly changing practice. Law schools should therefore change their approaches to teaching writing so that novices practice research and writing 
provide students the opportunity to engage in critical, thoughtful discussion about the characteristics of the human beings who make up the law-trained audience, the purposes and characteristics of particular types of legal writing, and the character that good lawyering, and justice, require. ${ }^{14}$

In the first section of the article, I present research regarding the image of the law-trained reader in some popular first-year legal writing textbooks, showing how these texts explicitly and implicitly instruct first-year law students regarding an image of the law-trained reader as impatient, aggressive, and unduly formalistic. ${ }^{15}$ In the next section, I argue that legal writing teachers should stop relying on such generalizations about the "law-trained reader" in their teaching first, because such generalizations are not an effective way to help students learn to write for the "law-trained reader," and second, because such generalizations can devolve into indoctrination in traits that are not necessary and not beneficial in many contexts, and that we therefore should not pressure all students to emulate. Finally, in the concluding section, I suggest better methods for helping first-year law students imagine the audience for their writing.

throughout law school, receive steady and expert feedback, and graduate competent and comfortable to begin whatever legal career they choose."

See, e.g., Rideout and Ramsfield, supra note 2, at 98.

${ }^{14}$ See Rideout and Ramsfield, supra note 2, at 98.

${ }^{15}$ See infra section I. 


\section{The Image of Lawyers in Legal Writing Textbooks: Impatient, Hyper-Critical Formalists}

.Many popular first-year legal writing textbooks ${ }^{16}$ speak quite directly about the personal characteristics of members of the law-trained audience. Three purported lawyer characteristics in particular emerge from the descriptions of the law-trained audience in these tests, namely that lawyers are (1) extraordinarily busy and impatient; (2) hyper-critical, and aggressive in their criticism; and (3) bent on a conservative, strict application of formal rules. ${ }^{17}$ In many texts, this third characteristic, formalism, is bolstered by instruction that students should carefully adhere to some version of the "IRAC" formula in ordering their sentences and paragraphs throughout written legal analysis. ${ }^{18}$

\section{A. The first shared trait: extraordinary impatience.}

The first characteristic, lawyers' extraordinarily cramped schedules and related impatience, is probably the most frequently mentioned characteristic of lawyers in the first-year textbooks. Lawyers' intellectual impatience is invoked

\footnotetext{
${ }^{16}$ I turned to the legal writing textbooks commonly used in first-year legal writing courses for evidence regarding the purported assumptions and preferences of the legal discourse community. I focused especially on three popular texts with which I have become particularly familiar in my own teaching: Linda H. Edwards, Legal Writing AND ANALysis (2003); Richard K. NeumanN, Legal Reasoning and Legal Writing: Structure, Strategy, and Style (5 $5^{\mathrm{TH}}$ ED. 2005); and Helene S. Shapo, Marilyn R. Walter, \& Elizabeth Fajans, Writing and Analysis in the LAW (rev. $4^{\text {th }}$ ed. 2003). None of the concerns expressed in this paper diminishes my great respect for the authors of these texts. Each has been a pioneer in the legal writing field, and I focused especially on these texts largely because I think each of them can be a strong tool for teaching legal writing, and because each has influenced my own teaching.

My intention in this paper is to criticize legal writing education that presents students with an overgeneralized image of the law-trained reader, without encouraging students to reflect about that image. I recognize and hope that many legal writing teachers, including the authors of the texts I examine in this paper, already provide a balanced, nuanced image of the law-trained audience in class or in other interactions with their students.

${ }^{17}$ I cannot help but wonder if these characteristics are more accurate descriptions of the members of the legal writing teachers' community than of law-trained readers in general. I have had the experience of inviting practitioners to speak to my legal writing classes to give a "real-world" perspective and then standing by as some speakers offer a much more laid-back, dare I say sloppy, approach to matters such as grammar, punctuation, and citation form than I take myself. And when I imagine the stereotypical legal writing teacher, I imagine some harried, red-pen-toting, grammarloving soul like myself.

${ }^{18}$ See infra, section I.C.
} 
as a reason why legal writing must be concise. For instance, in discussing readers" "attention levels," 19 Linda Edwards emphasizes that "these [law-trained] readers are extraordinarily busy." ${ }^{20}$ She goes on to explain that readers' attention level "is greatest in the first several pages, and [] decreases rapidly from then on," 21 and that "attention levels revive a bit at internal beginnings and endings." 22 It is not clear from the text what an "ordinary" level of busyness is, but the reader is invited to imagine lawyers and judges as "extraordinarily" busy and impatient.

In his first-year legal writing textbook, Richard K. Neumann creates a not too different picture of the average lawyer or judge as a reader, ${ }^{23}$ when he emphasizes that "lawyers and judges are busy people who do not have time to wade through poor writing." ${ }^{4}$ Thus, Neumann asserts that "[l]egal writing should give the viewer a quick and clear view, without distractions, of the idea behind it" 25 and must also "be able to withstand attack from what has been call the "reader in bad faith," such as "opposing attorney" or "unsympathetic judge." 26 Neumann further explains that "the reader must make a decision and wants from you exactly the material needed for the decision - not less and not more," and that "the reader is a busy person, must read quickly, and cannot afford to read twice." 27 Once again, the student is left with the impression that, more so than other professionals or academics with whom they might be familiar, lawyers are extraordinarily busy and cannot be expected to "wade through" slowmoving writing.

Textbooks authored by Nancy L. Schulz and Louis J. Sirico, Jr. offer a similar portrait. ${ }^{28}$ Schulz and Sirico emphasize that "[m]any lawyers frustrate

${ }^{19}$ EDWARDS, supra note 16 , at $70-71$.

${ }^{20} I d$. (emphasis added).

${ }^{21} I d$. at 70 .

${ }^{22} I d$.

${ }^{23}$ NeUmanN, supra note 16 , at 53-58.

${ }^{24} \mathrm{Id}$. at 52 .

${ }^{25} \mathrm{Id}$. at 51.

${ }^{26} I d$. at 52.

${ }^{27} \mathrm{Id}$.

${ }^{28}$ NANCy L. Schultz \& Louis J. Sirico, JR., Persuasive Writing FOR LaWyers AND the Legal Profession (1995) [hereinafter Schultz \& Sirico, Persuasive Writing]; and NANCy L. Schultz \& Louis J. Sirico, JR., Legal Writing and Other LaWyering Skills [hereinafter Schultz \& SiRICO, LEGAL WRITING]. 
judges by not adequately considering their needs and limitations," and that "[j]udges are busy people who need lawyers to give them clear, succinct, wellsupported, and well thought out reasons for deciding a case in a particular way." 29 Likewise, "the reader is most often a very busy person who does not have the time or patience to ferret out what you are trying to say." 30 Thus, "if you do not get to the point immediately, you will lose your reader at the outset.",31

Virtually the same message is delivered in the Shapo textbook; first, the typical attorney "will be very busy and will have certain expectations that you must fulfill" when writing a research memorandum. ${ }^{32}$ As for judges, because they "play the crucial role in litigation, it is worth your time and effort to consider carefully what information they need from your trial and appellate documents, and how that information can be clearly and quickly communicated." 33 Trial judges are "very busy."34

Charles Calleros agrees, urging the student to "consider the time pressures that a supervising attorney or judge faces; neither has time to glean from 20 pages ideas that you could have clearly expressed in 10." 35 Likewise, Mary Barnard Ray's text advises that "[ $\mathrm{t}] \mathrm{he}$ reader prefers clarity and readability over sophistication" and "[t]he reader wants to finish the document quickly.","

In short, one of the first and clearest messages to emerge from legal writing textbooks about lawyers is that they are "extraordinarily busy" professionals, seemingly more busy even than the average professional in the modern world; and that because of their busy schedules they are unusually impatient readers. ${ }^{37}$

\footnotetext{
${ }^{29}$ Schultz \& Sirico, Persuasive Writing, supra note 28, at 83.

${ }^{30} \mathrm{Id}$.

${ }^{31}$ Schultz \& SiRICO, LegAl Writing, supra note 28, at 123.

${ }^{32} \mathrm{Id}$. at 142 .

${ }^{33} I d$. at 331.

${ }^{34} I d$. at 344 .

${ }^{35}$ Charles R. Calleros, Legal Method and Writing 5 (2006).

${ }^{36}$ MARy BARnARd RAy, The BASICS OF Legal Writing 8 (2006).

${ }^{37}$ On the other hand, at least one legal writing textbook offers a more nuanced discussion of the time pressures and attention levels of members of the legal audience, noting, for example, that a trial judge reading a brief sees the case as "only one of many cases that require the judge's attention," as opposed to an attorney in one's own firm, who "may take the extra time to try and
} 


\section{B. The second shared trait: hypercritical, and aggressive about it.}

A second shared characteristic that some popular legal writing textbooks ascribe to legal readers is aggressive skepticism. Neumann, for instance, blatantly describes the legal reader as "aggressively" critical, pointing out that an attorney may attempt to distort language in an opponent's writing or that a judge may purposefully search for misstatements. ${ }^{38}$ Specifically, "the reader is aggressively skeptical and - with predatory instincts - will search for any gap or weakness in your analysis." 39

Edwards similarly refers to lawyers' aggressive skepticism when instructing students about the need for "road maps" 40 (introductory passages that foreshadow the structure of the analysis to follow) in legal writing. Edwards acknowledges that "[m]ost readers want a roadmap," an even greater need for an organizational structure." 42 The several reasons for this greater need among law-trained reader include that (1) "an outline" of the applicable law is "basic to the way law-trained readers think,"43 (2) "[1]awyers and judges do not read the law out of intellectual curiosity but because they have a problem to solve," ${ }^{44}$ (3) "a law-trained reader reads skeptically, constantly assessing the strength and accuracy of the analysis and the credibility of the writer," and (4) "[1] aw trained readers are not comfortable with organizational surprises." Edwards further asserts that judges are "particularly [skeptical]"

figure out the analysis you present in a memo." And at least one legal writing textbook acknowledges the likelihood that many clients and jury members experience as many great pressures on their time as lawyers and judges. See Bradley G. Clary \& Pamela Lysaght, Successful Legal AnAlysis AND Writing: The Fundamentals iii (2003) ("[A]udiences these days [i.e., juries, judges, clients, agencies, colleagues, and adversaries] often share some of the following characteristics: They are busy. They have too much to do and too little time in which to do it.")

${ }^{38}$ Id. at 54.

${ }^{39} \mathrm{Id}$. at 52.

${ }^{40}$ EDWARDS, supra note 16 , at 70-71.

${ }^{41} I d$. at 71 .

${ }^{42}$ Id.

${ }^{43} I d$.

${ }^{44} I d$.

${ }^{45}$ Id.

${ }^{46}$ Id. 
readers. ${ }^{47}$ Thus, while acknowledging that most readers find it easier to read text that opens with a roadmap, Edwards asserts that such foreshadowing is even more important in legal writing, as an antidote to lawyers' aggressive skepticism.

Clary and Lysaght also emphasize lawyers' need to question and think critically, though they characterize that behavior in less aggressive terms, describing a good lawyer as "a good investigative reporter," ferreting out the "“who, what, where, when, why, and how" of the situation, and asking question after question. ${ }^{48}$

\section{The third shared trait: formalism.}

A third characteristic legal writing textbooks commonly ascribe to lawyers is personal conservativism, in the sense of an unusual concern with matters of form and format. The texts make both direct and indirect claims about lawyers' purported formalism.

\section{Explicit discussion of lawyers' "personal conservatism" and formalism.}

In an apparent effort to inspire students to be more careful about matters of form, many of these textbooks devote substantial space to admonishing new law students about the strictly formalistic outlook of the future readers of their legal writing. For example, Edwards emphasizes the need to keep the reader's inner voice (what she calls the "Commentator") "relatively quiet," asserting that, in particular, judges are even more "personally conservative" than the average lawyer. ${ }^{49}$ Neumann attempts to capture the students' attention with an even more vivid description, asserting that "the reader will be disgusted by sloppiness, imprecision, inaccuracy, or anything . . . that hints that you might be unreliable," and "will be conservative about matters of grammar, style, citation form, and

${ }^{47} I d$. at 73 .

${ }^{48}$ See Clary \& LySAGHT, supra note 38, at vii-viii (questions for self-critique), 13-15 (questioning the facts), 32-36 (questioning the law, including breaking a three-element rule into twenty-five elements). The Shapo text, more like Clary and Lysaght, describes lawyers as possessing "healthy" but not peculiarly aggressive skepticism. This text also notes that trial judges are bound to follow the precedents of [the] jurisdiction," with "questioning minds and healthy skepticism. SHAPO ET AL., supra note 16 , at 344 .

${ }^{49}$ EDWARDS, supra note 16 , at $72-73$. 
document format." ${ }^{, 50}$ Thus, Neumann adds a dash of inflexibility to the emphasis on lawyers' formalism.

The Shapo textbook likewise describes the legal reader as form-conscious. In addition to expecting "a core of information about the controlling law and its application to the facts of the problem," the audience for a memorandum will also expect "good written English," specifically "standard written English,"51 which Shapo leaves undefined. A new textbook from Mary Barnard Ray makes the point plainly and bluntly: "Legal readers are strict about format rules."

2. The formula for organizing legal writing: IRAC.

In addition to these explicit references, lawyers' purported bent for strict formalism gain implicit support from at least one other area of instruction in these books: the paradigm for legal analysis. These textbooks' advice to follow a rather inflexible organizational formula, the so-called "IRAC",53 paradigm or some variant of it, bolsters the stereotype that lawyers are formalist, even formulaic, in their thinking.

Many legal textbooks suggest that the IRAC formula is the organizational and analytical structure that can best be trusted to produce competent legal analysis. For example, Edwards' discussion of the legal paradigm opens with the announcement that "[a] legal rule is analyzed by first identifying and understanding the governing rule and then applying that rule to a particular set of

\footnotetext{
${ }^{50}$ NeUmanN, supra note 16, at 52 (emphasis added).

${ }^{51}$ SHAPO ET AL., supra note 16, at 142.

52 RAY, supra note 37. Later, Ray advises that with regard to citation rules, "[y]ou may find the details of the rules frustrating and wonder why they are so particular. The reason . . . is almost always efficiency or accuracy. For example, legal readers require citations after each sentence about the law so they can know accurately just how much comes from the cited source and how much is the writer's own reasoning." Id. This well-meaning advice to new students illustrates how difficult it is for legal writing teachers to make accurate statements about the shared characteristics of lawyers. The example Ray cites, whether it is necessary to provide a citation for every sentence, is used by Clary and Lysaght to illustrate that "reasonable people may differ" about such matters. See ClARY \& LYSAGHT, supra note 38.

${ }^{53}$ Douglas Litowitz argues that using IRAC system as a writing technique "creates the misleading impression that legal writing involves primarily the application of pre-existing rules to a static set of facts." LiTOWITZ, supra note 8, at 739.
} 
facts. First you must explain the rule; then you must apply that rule to the facts." "54 Thus, the paradigm is embraced as "the paradigm for legal analysis," even though the text later acknowledges that "[k]eeping the halves distinct does not mean that while you are engaged in the process of writing the paradigm you must complete rule explanation before you attempt to write any rule application. ${ }^{, 56}$

The Edwards text goes on to identify two sections and five individual components of a "paradigm for a working draft." Explanation," has three components:

Conclusion: State your conclusion about the issue.

Rule: State the applicable rule of law.

Rule Explanation: Explain the rule. ${ }^{58}$

The second section, "Rule Application," has two components:

Rule Application: Apply the rule to your client's facts.

Conclusion: Restate your conclusion. ${ }^{59}$

The text then provides direction about how to write each component. As for the conclusion, "[1]aw-trained readers are impatient to learn your answer, so the first thing your reader will want to see is your conclusion."60 Edwards then suggests an "introductory paragraph," restating the conclusion in two or three

\footnotetext{
${ }^{54}$ EDWARDS, supra note 16 , at 89.

${ }^{55} \mathrm{Id}$. at 90 (emphasis added.)

${ }^{56} I d$. at 90 .

${ }^{57} \mathrm{Id}$. at 89.

${ }^{58} \mathrm{Id}$.

${ }^{59} \mathrm{Id}$.

${ }^{60} \mathrm{Id}$. at 90.
} 
sentences. ${ }^{61}$ After that, "state the governing rule," which "[u]sually . . . should be the first sentence in the first paragraph after the introductory paragraph.",62

Edwards concedes that "[o]ccasionally . . . an issue is complex enough to require a little context or clarification before stating the rule," but emphasizes the importance of stating the rule "as quickly as you can," not only because the reader is impatient, but also because "the discipline of concisely stating the rule immediately after the conclusion is an important part of your analytical process." ${ }^{\text {"6 }}$ The stated rule should be "the focal point of the first half of the analysis. $" 64$

The rest of the first half of the analysis should explain "where the rule comes from and what it means," by covering five "interrelated" steps: (1) "[s]how how the authorities demonstrate that the rule is what you say it is," (2) "[e]xplain the rule's purpose or the policies it serves," (3) "[e]xplain how the rule has been applied in the past, (4) "[e]xplain any additional characteristics that will affect how the rule may be applied," such as burdens of proof, and (5) "[t]o the extent necessary, explain any other possible understanding of the rule." ${ }^{\prime 5}$ This last step, "sometimes called "counter-analysis' or 'counter-explanation," is necessary "[i]n persuasive writing . . . [if it] is reasonably likely to arise.",66

Neumann's text encourages students to adopt a similar organizational strategy in their writing. In the opening paragraphs discussing organization of legal analysis, the text asserts that a legal analysis delivered in the same order in which it was reasoned out, that is, facts-law-conclusion, is not an analysis that "could be read by another lawyer." 67 Neumann asserts that something about the presentation must change to make the analysis appropriate for the law-trained audience. The text goes on to say that the appropriate paradigm for this legal audience is to "prove a conclusion of law and the facts in ways that convince the reader that your conclusion is the right one." 68 Once again, the formalist

${ }^{61} \mathrm{Id}$.

${ }^{62} I d$. at 92 .

${ }^{63} \mathrm{Id}$.

${ }^{64}$ Id.

${ }^{65} \mathrm{Id}$. at $92-93$.

${ }^{66} \mathrm{Id}$. at 93

${ }^{67}$ NeUmanN, supra note 16.

${ }^{68}$ NeUMANN, supra note 16 , at 100. 
approach is portrayed as necessary to appease the rigid reader, as lawyers and judges will "both look for a tightly structured analysis that makes your conclusion seem inevitable." ${ }^{\prime 9}$

Moreover, Neumann suggests that these readers need the information underlying the analysis to be delivered in a particular order: "first . . . your conclusion . . . ; then the main rule (or rules) on which your conclusion is based; next, proof and explanation that the rule exists and that you have stated it accurately; and then application of that subsidiary rules to the facts." ${ }^{, 70}$ The author explains later in the chapter "Why Readers Prefer This Type of Organization": ${ }^{71}$

Remember that all of your readers will be practical and skeptical people and will be reading your memorandum or brief because they must make a decision.

State your conclusion first because a practical and busy reader needs to know that you are trying to support before you start supporting it. . . . Effective writers usually state their conclusions boldly at the beginning of a Discussion or Argument. . . . This may take some getting used to. It is contrary to the way writing is often done in college. And most of us have been socialized since childhood to state a conclusion only after a proof - even in the most informal situations - to avoid appearing opinionated, arrogant, or confrontational. ...

State the rule next because, after reading a conclusion of law, the skeptical law-trained mind instinctively wants to know what principles of law require that conclusion instead of others. After all, the whole idea of law is that things are to be done according to the rules.

Then prove and explain the rule because the reader will refuse to follow you further until you have established that rule is really

\footnotetext{
${ }^{69} I d$.

${ }^{70}$ Id. at $100-101$.

${ }^{71} \mathrm{Id}$. at 103.
} 
law the way you say it is and until you have educated the reader somewhat on how the rule works. The skeptical law-trained mind will not accept a rule statement as genuine unless it has been proved with authority. ...

Apply the rule last because that is the only thing left. . . ${ }^{72}$

Other authors offer similar formulaic approaches to organizing legal analysis in writing. Schultz and Sirico explain that "the way to organize is to write according to an outline and to put your conclusions first." ${ }^{, 73}$ And Shapo presents a pattern that is a "fairly standard format for fact-based legal problems because it logically orders the steps necessary in this type of legal reasoning." briefly acknowledging that issues involving "the meaning or the validity of a law, for example," may require a variation of the pattern, Shapo asserts that

[A] useful pattern for analyzing a single legal issue often has the following structure:

1. Explanation of the applicable rule of law

2. Examination of how the rules is applied in the relevant precedents

3. Application of the law to the facts of your case and comparison with the precedents

4. Presentation and evaluation of counterarguments

\section{Conclusion ${ }^{75}$}

According to Shapo, "[a]dherence to this pattern ensures that the reader gets necessary information in an order which is readily understandable. You should not begin the discussion with a summary of the facts of your case . . . because the

${ }^{72} I d$. at 103.

${ }^{73}$ SCHULTZ \& SiRICO, supra note 28.

${ }^{74}$ SHAPO, supra note 16 , at 113.

${ }^{75} \mathrm{Id}$. at 114 . 
reader cannot assess the legal significance of those facts without your having first explained the controlling rules and examined the relevant case law . . .,"76

The introductory summary of the paradigm in the Shapo text differs from the summaries of the paradigm in Edwards and Neumann, but those differences are less significant than they first appear. Specifically, though Shapo does not indicate that the writer's conclusion must be stated at the outset of the analysis, this difference is less significant than it seems at first because in the following chapter, Shapo indicates that an entire "thesis paragraph" should begin the legal analysis. ${ }^{77}$ In the thesis paragraph, the writer should set forth her "reasoned conclusion" of law after introducing the client's claim and the legal issues involved. $^{78}$

Like other texts, Shapo's text describes in some detail exactly the sort and even number of sentences that should appear within each component of the paradigm. First, "[t]he discussion of a particular legal issue should begin with a sentence or one or more paragraphs that set forth and explain the governing rule of law."79 Then, after analyzing the governing rule of law,

your next step is to examine the relevant case law from which that rule came or in which it has been applied. In a fact-based problem, you should recount the relevant facts of the precedents because it is by identifying how the rules of law were applied to the facts of those cases that you give the rules meaning. ${ }^{80}$

Then, "you should set out and evaluate the similarities and differences between the precedent and your case and determine their importance. . . . [and] should also apply the reasoning or policies of a decided case to your own case." ${ }^{\prime 1}$ After giving appropriate consideration to counterargument, "[t]he final sentence should be the legal conclusion, a conclusion grounded in the prior analysis of the law, precedent, and facts. This conclusion differs from the one given in the

\footnotetext{
${ }^{76} I d$.

${ }^{77}$ Id. at 131 .

${ }^{78} \mathrm{Id}$.

${ }^{79}$ SHAPO, supra note 16 , at 115.

${ }^{80} \mathrm{Id}$. at 116.

${ }^{81} \mathrm{Id}$. at 117.
} 
thesis paragraph .... [which] offers an assessment of a client's overall chance of winning a suit or defending himself against a charge." 82

In short, many first-year legal writing textbooks instruct students to adopt an extremely formulaic approach to organizing writing about legal problems.

3. IRAC as the formula for legal reasoning.

Some passages in these texts seem to go beyond offering the formula as merely an organizational tool, to presenting the IRAC formula (or similar formulas) as a sort of jurisprudence, an embodiment of the process of legal analysis - assuming, for instance, that legal analysis revolves around identifiable rules, and that legal reasoning is a clockwork process of articulating the appropriate rule and then applying it to the material facts that present themselves.

For example, Edwards' discussion of the first half of the paradigm (explanation of the rule), seems to assume that one or more rules can be readily identified to govern any legal issue, and that articulating the rule only rarely requires context or clarification. This advice, that the first half of any written legal analysis should state and then explain an identifiable "rule," is balanced to some degree by other portion of the Edwards text, which presents a more complex view of legal analysis. In chapter five of her book, "Forms of Legal Reasoning," Edwards describes "a number of kinds of logical reasoning" common in the law. ${ }^{83}$ These include "rule-based reasoning," "analogical reasoning," "policy-based reasoning," "custom-based reasoning," and "principlebased reasoning." 84 Edwards also acknowledges another "way lawyers advocate for a result: narrative," ${ }^{85}$ noting that although "[t]oday, we usually use the term 'reasoning' to describe only logical processes like those described above, . . . an earlier understanding of 'reasoning' was much broader .... [and] included processes that transcend logical arguments and may even resemble intuition."

${ }^{82} I d$. at 119 .

${ }^{83}$ EDWARDS, supra note 16, at 55.

${ }^{84}$ Id.

${ }^{85} \mathrm{Id}$.

${ }^{86} I d$. 
Nonetheless, Edwards makes clear that rules are at the top of the hierarchy of these forms of reasoning, at least in the rule and rule-explanation portions of the paradigm. ${ }^{87}$ It is only in the second half of the analytical paradigm that Edwards advises students to incorporate other, non-rule based forms of reasoning.

Yet even in advising how to write the rule application section, Edwards begins with the advice that "this half of the paradigm uses the deductive format of syllogistic reasoning - that is, applying a general, often abstract principle to a particular situation and arriving at a conclusion." 88 Thus, "rule-based reasoning is still important," but "narrative, analogical, . . policy and principle-based . . ., and custom-based reasoning are at least as important. $"{ }^{\circ 9}$

Edwards' specific advice about how to complete the rule application further diminishes the importance of non-rule based reasoning. She advises that "a written legal analysis ultimately should be framed in tightly reasoned logic," though acknowledging that the structure might be less tight during the drafting process. ${ }^{90}$ She also suggests that some might begin "by focusing on the narrative" with "the rule in mind, but more impressionistically so." 91 In the end, though, "revise [the two halves] so the rule explained in the first half matches the rule applied in the second half," with "the end result ... [of] a logical analysis built upon a narrative theme." 92

Neumann's textbook also implies that the formula is more than an organizational tool. Neumann acknowledges that the paradigm may sometimes be varied, ${ }^{93}$ but limits the variations: (1) "you can vary the sequence in which the components appear," (2) "in the rule proof and in rule application, you can vary the depth of your explanation to suit the amount of skepticism you expect from the reader," and (3) you can combine separately paradigmed analyses into a

${ }^{87} \mathrm{Id}$. ("[r]ule-based reasoning is the starting point for legal analysis”).

${ }^{88} I d$. at 101.

${ }^{89} I d$.

${ }^{90} \mathrm{Id}$.

${ }^{91} \mathrm{Id}$. at 102.

${ }^{92} \mathrm{Id}$.

${ }^{93}$ NeUmanN, supra note 16, at 104. 
unified explanation of several issues and sub-issues." $"$ None of the variations refer to the use of non-rule based reasoning to create a more in-depth argument.

Similarly, instruction in the Shapo text supports a factory-like, rule-to-result form of legal analysis, even though the Shapo text presents the paradigm as somewhat less settled and absolute than it seems to be in Edwards and Neumann. At the outset, the Shapo test takes a less strident approach about the writer's need to follow the suggested paradigm; the authors merely "suggest [that this] organizational pattern [] will enable you to write a clear analysis" of an issue." $" 95$ Also, throughout the description of how to write according to the paradigm, the authors repeatedly acknowledge that the writer will have to make decisions about what is appropriate to the particular legal discussion at issue. ${ }^{96}$

Shapo does describe the paradigm as "a fairly standard format for fact-based legal problems because it logically orders the steps necessary in this type of legal reasoning," and strongly recommends that students "adhere[]" to the paradigm, because this is an order "in which it is readily understandable." Also, despite the repeated emphasis on the need for the writer to consider the requirements of the particular legal analysis at issue, the Shapo text is even more specific than Edwards or Neumann about what should appear in particular sentences. The suggestion that the first and last sentences of written legal analysis should always cover the same basic content creates the impression that the analysis structure is formalistic, even formulaic.

In summary, instruction regarding rigid adherence to the IRAC paradigm in ordering paragraphs and even sentences throughout written legal analysis lends further support to the depiction in these textbooks of lawyers as almost foolishly formalistic in their approach. As Neumann states, "the whole idea of law is that things are to be done according to rules," and in these textbooks even the process of legal reasoning seems to be governed by rule.

\footnotetext{
${ }^{94} I d$.

${ }^{95}$ SHAPO, supra note 16.

${ }^{96}$ For example, they state that "for most issues ... you will need to break your analysis into parts," but suggest that a single paragraph sometimes will cover all of the parts. Id. at 114 .
} 


\section{What Is the Trouble with Relying on this Image of the Law- Trained Reader?}

One possible response to these textbooks' reliance on such generalizations and formulas in legal writing education is simply, "so what." Legal writing textbooks do not embody the whole of legal writing education, and the legal writing teachers who use these textbooks surely supplement the reading with classroom discussions about the audience and purpose for each particular writing assignment.

Additionally, one might ask, even if these generalizations about the "lawtrained reader" are not accurate ${ }^{97}$ (and even if one does not think that these traits of impatience, aggression, and formalism are always, necessarily, traits of good lawyering), what harm can these generalizations really do? Legal writing teachers must say something about the audience for which their students expect to be writing, and none of us can have a completely accurate perspective of the complicated, diverse audience students will face. Given the situation legal

${ }^{97}$ It seems obvious that such broad generalizations cannot accurately describe the attitudes and preferences of the individual lawyers, judges, and other readers whom our students encounter. And though the available studies of law-trained readers' preferences about legal writing do suggest a shared desire for concise, clear writing, none of the studies establishes overwhelming impatience, aggression, or formalism as shared traits. For example, one study recently "surveyed members of the academy, bench, and bar to see what they thought of the writing skills of law graduates," Susan Hanley Kosse and David T. ButleRitchie, How Judges, Practitioners, and Legal Writing Teachers Assess the Writing Skills of New Law Graduates: A Comparative Study, 53 J. Legal Educ. 80, 80 (2003), and found agreement among all three groups agree that "most legal writing is weak," id. at 85, and that "clarity and concision [rank as] the two most essential elements of good writing," id. Other interesting surveys of various portions of the legal audience include Bryan A. Garner, Judges on Briefing: a National Survey, 8 Scribes J. Leg. Writing 1, 2-3 (2002) (surveying state and federal judges and discovering that they tend to believe that "[a] brief should be an essay with a clear train of thought" as opposed to "a repository of all the information that a curious judge might want to know about the case"); Susan McClellan and Constance Krontz, Improving Legal Writing Courses: Perspectives from the Bar and Bench, 8 Leg. Writing 201, 203, 222 (2002) (surveying "judges and practicing attorneys who supervise the work of first-year associates or judicial law clerks" and concluding from the survey responses that, among other things, "[law school] training should emphasize how to organize a coherent legal argument that moves smoothly, persuasively, and concisely from one point to the next"); Kristen K. Robbins, The Inside Scoop: What Federal Judges Really Think About the Way Lawyers Write, 8 Leg. Writing 257, 284 (2002) (surveying federal judges and concluding that "advocates need to engage in hard-hitting, intelligent, and honest legal analysis" using "'tried and true' organizational forms" and being "concise and clear"); David Lewis, Common Knowledge about Appellate Briefs: True or False?, 6 J. App. Prac. \& Process 331 (Fall 2004) (surveying appellate judges about their preferences in appellate briefs). 
writing teachers find themselves in, one might argue that the best legal writing teachers can do is to discuss the topic of audience in general terms, and assume that through their writing assignments and later experiences students will learn to modify their writing appropriately for different audiences they encounter.

To the contrary, I think that the tendency in these popular textbooks to overgeneralize about "what lawyers are like" is a serious concern. Legal writing education is important, and legal writing teachers can do better.

\section{A. Reliance on generalizations about the audience for legal writing is an ineffective way to help students improve their legal writing.}

It is easy to imagine why legal writing teachers might tend to over-generalize about the personalities of practicing lawyers in their classrooms. Members of the legal writing field themselves remain unsure about the field's substance, about whether "legal writing" is a legitimate field of scholarship different from the substance of the topical law courses. ${ }^{98}$ And in this uncertain, insecure context, information about the preferences of the audience for whom students will be writing is one area of information over which legal writing teachers have some legitimate claim to specialized knowledge. Most of us were hired specifically because of our expertise in legal writing, in particular because of our practice experience and success with legal writing. Indeed, some legal writing teachers may consider their knowledge of "what lawyers are like," and in particular, "what lawyers like in legal writing," as the basis for all of their teaching and scholarship, as their reason for being part of the law school. ${ }^{99}$

\footnotetext{
${ }^{98}$ For an interesting discussion of the traditional (and somewhat paradoxical) opinions about legal writing education and why it should remain separate and different from the rest of the law school curriculum, see Rideout and Ramsfield, supra note 2, critiquing the views that "writing is writing," at 41-42, "writing can't be taught," at 43-44, "writing is ancillary to the real law," at 44-45, "legal writing is legal drafting," at 46-47, and "teaching legal writing is anti-intellectual," at 47-48.

And for a recent view, from a legal writing teacher, that "the substance of legal writing itself [is not] a viable field for legal scholarship, because of the lack of a doctrinal-law basis for the subject," see Mitchell Nathanson, Taking the Road Less Travelled: Why Practical Scholarship Makes Sense for the Legal Writing Professor, 11 LEGAL WRITING 329, 330 n. 5 (2005).

${ }^{99}$ See, e.g., Nathanson, supra note 99, at 358 (arguing that "the wealth of practical knowledge stored within the combined legal writing professoriate should be tapped so as to enable us to step in and help round out the modern law students' legal education).
} 
Even teachers who do not consider their opinions about "what lawyers are like" to be the primary basis for their teaching might think it necessary to discuss generalizations about the audience as the first step in the "process" approach to teaching writing. Identification of demographic and other information about the nature of the audience is often suggested as a first step in the "process" approach to writing education, ${ }^{100}$ an approach that made strong inroads into legal writing pedagogy in the 1980's and 1990's. ${ }^{101}$

Yet another pedagogical reason for relying on these traits is to motivate students to write more clearly and concisely and be more careful about matters of form. In particular, the emphasis on lawyers' impatience in the textbooks discussed above seems aimed at motivating students to write clearly and concisely. ${ }^{102}$ Likewise, the texts' emphasis that lawyers are strict about errors of form and format could be aimed at motivating students to follow those rules in their legal writing assignments. ${ }^{103}$

Other, non-pedagogical reasons may also help explain legal writing teachers' tendency to opine about "what lawyers are like." Despite recent gains, legal writing teachers remain at most schools on a separate and unequal track of the legal academy. ${ }^{104}$ Yet, the average legal writing professor has more practice experience than the average doctrinal professor. ${ }^{105}$ Legal writing teachers' greater experience with other lawyers in practice might cause them to feel especially confident about their teaching as it relates to knowledge of "what lawyers are like" in practice settings. ${ }^{106}$ Claiming expertise about "what lawyers

\footnotetext{
${ }^{100}$ See Reiff, supra note 6, at 101-02.

${ }^{101}$ See Rideout and Ramsfield, supra note 2.

${ }^{102}$ See supra section $\mathrm{I}(\mathrm{A})$.

${ }^{103}$ See supra section $\mathrm{I}(\mathrm{C})$

${ }^{104}$ ALWD SURVEY 2006.

105 See Nathanson, supra note 99 at 338 (describing survey finding that legal writing professors had, on average, 7.4 years of law firm practice experience, while so-called "doctrinal" professors averaged 3.5 years of such experience).

${ }^{106}$ See id. at 375-76 ("Legal writing professors first need to recognize their unique area of expertise among law faculties, and then stand up and be counted. A concerted effort needs to be made to highlight our unique skills to our administrations and doctrinal colleagues and to impress upon them the scholarly importance of these skills. It is crucial that they understand that although our skills may make us different than them, they do not make us lesser scholars or our presence on our faculties any less vital to the education of our students and service to the greater legal community.")
} 
are like," and even more specifically, "what lawyers like in their writing," legal writing teachers may feel they have legitimate authority.

Unfortunately, legal writing teachers' claim to authority regarding "what lawyers are like" is suspect. A fundamental problem is that each of us only has limited experience from which to draw. Our own practice experience, no matter how long and varied it might have been, is necessarily limited to the experience of one human being in a series of specific professional contexts. Transmitting that experience to our students cannot be sufficient to prepare students for the wide variety of experiences they will face in their own professional lives. Whatever generalizations we might have reached in our own minds about "what lawyers are like." based on own experiences, those generalizations will never be a perfect match for the varied context our students will find themselves in. In fact, if such generalizations are all we have to offer, they might not be much help at all, at least not for students who practice in different areas than we did.

Reasoning similarly, composition scholars have attacked the idea of "audience analysis" as it developed in some process approaches to English composition education, at least to the extent audience analysis "posits an abstract, generalizable collectivity." "107 These critics argue that "[i]nstead of giving writers a 'one-size-fits-all-readers' approach to audience, [writing teachers] need to enable them to navigate the multiple reading roles that they will likely encounter as communicators in various disciplinary and professional contexts."108

The same criticism could be leveled at the characterizations of the "lawtrained reader" in the legal writing textbooks surveyed in section I. Instead of giving legal writers a one-size-fits-all-readers approach to the audience of lawtrained readers, legal writing teachers should enable students to navigate the multiple reading roles they are likely to encounter in various professional contexts after law school. In the effort to help students learn to navigate those roles and contexts, legal writing teachers can and should share their own professional experiences. But to suggest that what students need to keep in mind when imagining those roles and contexts is a set of shared traits like impatience, aggression, and formalism, seems unlikely to be of much help.

\footnotetext{
${ }^{107}$ See Reiff, supra note 6, at 102.
}

${ }^{108} \mathrm{Id}$. at 104 . 
Indeed, the fact that many students probably find such generalizations about the audience unhelpful is another problem with relying on the generalizations. At least some students probably recognize almost immediately that the truth about "what lawyers are like" is much more complicated and interesting than over-generalizations like these. ${ }^{109}$ Such critical thinking fortunately should help inoculates students from the risk of indoctrination or pressure to conform to the over-generalizations. ${ }^{110}$ But it also should lead such students to doubt legal writing teachers' credibility.

And students should question the teaching that lawyers are impatient, aggressive, hyper-formalists. These traits themselves are not necessary, or even good, aspects of being a lawyer, at least not in all contexts. For example, as for impatience - of course lawyers, like so many professionals today, feel busy and time-pressured, and of course they become impatient with unclear, disorganized, or wordy writing. But at the same time, much legal work demands great patience, such as patience with the tedium of reading legal opinions and statutes; and patience to hear the stories of clients or litigants, listening well enough to ask the important questions. A particular lawyer's impatience while reading a particular memo thus should not be attributed to the fact that lawyers are extraordinarily impatient people.

Likewise, with aggressive criticism; of course legal analysis demands that we think critically about the basis for a legal argument, breaking it down into its component parts, looking for holes in it. And of course some contexts demand that some lawyers behave aggressively, zealously advocating for their client's rights and desires. At the same time, we can easily imagine other situations and contexts in which a lawyer's ability to find common ground with adversaries or among competing interests is more important, such as when litigation is first threatened against a client. Thus, a particular reader's aggressive criticism while reading a particular legal document is not wholly attributable to the fact that the reader went to law school.

\footnotetext{
109 Some students probably know a few lawyers who are patient, consensus-oriented, or a little sloppy in matters of form. Some may know lawyers who exhibit all three traits, and yet still manage to have fairly successful careers as lawyers. For instance, students have occasionally questioned me about some of these generalizations in their textbooks during office hours, or after class.

${ }^{110}$ See infra section II(B).
} 
Perhaps the worst thing about relying on such faulty over-generalizations about "what lawyers are like" is the missed opportunity for real learning. If in our textbooks and our classrooms we paint the "law-trained reader" with such a broad brush, even if we do not convince students that our image of the audience is accurate, we still miss an opportunity to model the sort of critical thinking we should be helping our students learn. We also miss an opportunity to help students practice grappling with the "complex and shifting roles of readers" their legal writing.

In short, legal writing education would be more effective if, instead of teaching students to imagine a monolithic audience with shared traits such as impatience, aggression, and formalism, it engaged students in more complicated, careful thought about the audience for legal writing. Legal writing education should acknowledge the multiple perspectives and motivations that different lawyers bring to the varied reading roles and contexts they face in the profession.

\section{B. Reliance on generalizations about the audience for legal writing creates unnecessary and inequitable pressure to conform.}

Even if teaching about generalized traits were an effective way to help students to learn to write about the law, there remains another problem with these textbooks' over-generalizations about the law-trained reader. Because legal writing education focuses so explicitly on helping students develop the skills to explore and create legal discourse - that is, the vocabulary, evidence, and arguments that can succeed in the law, that other lawyers will recognize as "legal" - our teaching runs a particular risk of devolving into indoctrination in the current conventions of legal discourse. ${ }^{12}$

\footnotetext{
${ }^{111}$ Reiff, supra note 6, at 102.

112 See Stanchi, supra note 8, at 10 ("In the legal writing context, the dilemma for the teacher is whether the teacher should 'socialize' the student to the culture and language of law, thereby risking that the already marginalized will be further marginalized. ... . [thereby] contributing to the suppression of certain unique and valuable voices, cultures and concepts in law, and ensuring that law remains a language of power and privilege. On the other hand, if students are not socialized, have legal writing teachers 'set up' already marginalized students to fail in legal practice?")

See also Baker, supra note 12, at 516-17 (emphasizing the "great[] challenge to meet the expectations of socialized and privileged legal decision-makers," who are "infused with the hegemonic rules of culture and law; [and] have conscious and unconscious perspectives, ideologies,
} 
Of course many, perhaps even most, lawyers are busy professionals, of course legal analysis requires critical thinking and analysis, and of course law practice sometimes requires precise attention to nitpicky formal rules. But there is also a place in law practice for patience, consensus, and pragmatism. ${ }^{113}$ Do we really think that almost all lawyers are so extraordinarily busy, so much busier than other modern-day professionals? Do we really think most of them read, say, the average office memo, with an aggressively critical eye? Do we really think most of them care much about citation format, or the occasional typographical error? And even if we answer all of these questions "yes," do we really want our students to be these kinds of lawyers?

Concern that legal education could silence or distort law students' voices and ultimately their contributions to the development of the law is a familiar theme in recent legal scholarship, including scholarship about legal writing. For example, the Texas Law Review published in 1988 a colloquy on "Human Voice in Legal Discourse." "In his essay opening the colloquy, Voices, Julius Getman asserts that legal education is focused mostly on helping students to develop a "'professional voice,' the essence of which is addressing questions of justice through the analysis of legal rules." 115 He claims that legal education overemphasizes the professional voice (and related voices, the critical and scholarly voices) at the expense of the so-called "'human voice,' by which [he means] language that uses ordinary concepts and familiar situations without professional ornamentation to analyze legal issues."

Although Getman acknowledges that "it is desirable, indeed crucial, that legal education teach professional voice and that legal scholarship utilizes it,"117

and commitments favoring the status quo and privileging certain narrative accounts, social rules, and forms of reasoning and argumentation.")

113 See, e.g., Guinier ET AL., supra note 8, at 84-87 (suggesting that "in light of the changing character of the legal profession" and the disparately negative impact of law teaching on female law students, the time has come "to reexamine traditional assumptions about lawyering," including the ranking of students "by testing analytical thinking exclusively in the abstract," "focus[ing] on legal issues exclusively or primarily in the context of . . litigation," and the fact that "a contemporary attorney may need more than the ability to spot issues or engage in quick-response timed legal analysis, as measured by blind-graded examinations.")

114 Julius G. Getman, Voices 66 Tex. L. Rev. 577-646 (1988).

${ }^{115}$ Getman, supra note 115 , at 577.

${ }^{116} \mathrm{Id}$. at 582.

${ }^{117} \mathrm{Id}$. at 578 . 
he argues that an "imbalance," 118 namely the "undervaluing of "human voice," 119 is bad for legal education, and bad for the law. ${ }^{120}$ Getman makes a particularly convincing case against elitism in academia, noting that "[a]cademics sometimes act as though thinking, intellectual creativity, and enthusiasm for ideas are the special province of the professionally certified," and recounting his personal experience, in his own home as a child of parents who lacked any formal education and in his work with steelworkers and other workers. ${ }^{121} \mathrm{He}$ notes, for example, that he has never found "a group of workers too simple to understand the intricacies of the law."

${ }^{118} I d$. at 577 .

${ }^{119}$ Id. at 582 .

${ }^{120}$ For instance, discussing Susan Estrich's article Rape, which begins with the author's description of her own experience as a rape victim, Getman focuses on the contrast between the voices of the victim and the judges in Rusk v. State. See id. at 586-87. Quoting Estrich's article, Getman provides the following passages, the first in the rape victim's human voice, the second in the professional voice of the judges issuing their opinion that the victim did not resist sufficently:

I said, 'you can get a lot of other girls down there, for what you want,' and he just kept saying, 'no,' and then I was really scared, because I can't describe, you know, what was said. It was more the look in his eyes; and I said, at that point I didn't know what to say; and I said, 'If I do what you want, will you let me go without killing me?' Because I didn't know, at that point, what he was going to do; and I started to cry; and when I did, he put his hands on my throat, and started lightly to choke me; and I said, 'If I do what you want, will you let me go?' And he said, yes, and at that time, I proceeded to do what he wanted me to do.

$* * *$

While courts no longer require a female to resist to the utmost or to resist where resistance would be foolhardy, they do require her acquiescence in the act of intercourse to stem from fear generated by something of substance. She may not simply say, 'I was really scared,' and thereby transform consent or mere unwillingness into submission by force. These words do not transform a seducer into a rapist. She must follow the natural instinct of every proud female to resist, by more than mere words, the violation of her person by a stranger or an unwelcomed friend. She must make it plain that she regards such sexual acts as abhorrent and repugnant to her natural sense of pride.

Getman notes that "[i]t is difficult not to be outraged at the calm use of professional voice in this [second] passage or to wonder what motivation lies behind it...." Id. (footnotes omitted).

${ }^{121}$ Getman, supra note 115 , at 587. In the same passage, Getman points out that "the issue of voice in legal discourse is related to a deeper issue: the relationship between ideas and credentials," $i d$.

${ }^{122} \mathrm{Id}$. at 588 . 
Getman's concerns seem particularly apt for legal writing teachers trying to help students imagine the audience for their future writing. As Getman implies, there is usually no logical reason that lawyers cannot use an ordinary "human" voice to communicate their arguments about the law. To the extent we teach our students that they must write especially concisely or organize each paragraph and sentence according to some particular formula, in order to successfully meet the shared expectations of law-trained readers, we not only mislead them, we might discourage them from using their own "human voice" to communicate about the law. Silencing those voices not only harms our students, it harms the law.

Worse yet, we probably discourage some voices disproportionately. Kathryn Stanchi has presented a forceful critique of legal writing pedagogy's tendency to "mute" the voices of groups traditionally underrepresented in the law. ${ }^{123}$ She notes that legal writing education has developed a "dual strategy" that focuses both on the process of producing legal communication for a particular audience, ${ }^{124}$ and the "acculturation of the novice legal communicator into the legal 'discourse community' through the learning of legal vocabulary, legal customs, and legal culture." ${ }^{\prime 25}$ Neither the process focus nor the socialization focus, however, offers much opportunity to engage students in critical thought about the audience they are writing for, or the vocabulary, customs, and culture they are asked to adopt:

Consistent with their goals of teaching effective lawyering 'in the real world,' neither. . . pedagogy questions the validity or motives of the external rules imposed by the audience, language, or context of law. Their purpose is to ease the students' entry into the community, not to challenge the customs or culture of the community." 126

Stanchi emphasizes how consistently "legal writing teaches that the most persuasive frameworks and theories tend to be those that are most

\footnotetext{
${ }^{123}$ Stanchi, supra note 8, at 9 ("because legal writing pedagogy reflects the biases in legal language (including legal reasoning), its effectiveness in 'socializing' law students comes at the price of suppressing the voices of those who have already been historically marginalized by legal language" (footnote omitted)).

${ }^{124} \mathrm{Id}$. at 8-9.

${ }^{125} \mathrm{Id}$. at 9 (footnote omitted).

${ }^{126} I d$. at 22 .
} 
mainstream," 127 citing advice in the Edwards textbook, already mentioned in this article, that "[1]awyers as a group tend to be personally conservative . . . [and t]his is particularly true of judges." 228 Her call for a more critical approach in the legal writing classroom applies especially forcefully to legal writing education that directly instructs students that the law-trained audience shares the stereotyped, traditional traits of impatience, hyper-criticism, and formalism. As Stanchi points out, the payoff of a more critical approach would be double:

not only will we teach our students to challenge biased language and send them out to the legal market with the tools they need to succeed and the encouragement to stretch language and think outside the box, but in doing so, we can make law school - and law practice - a less alienating place." 129

Interestingly, recent sociological research exploring alienation among students at professional schools suggests that the process of developing a professional identity during the first year of law school does indeed have a disproportionately negative impact on female law students, especially students of color. ${ }^{130}$ Working from the theory that professional study teaches not only specialized skills and knowledge of a profession, but also "the acquisition of an appropriate professional identity,"131 Carrie Yang Costello sought to examine whether "the process of incorporating a new professional identity varied for people with different personal identities." ${ }^{\text {"32 }}$ Her research confirmed the hypothesis that "[s]tudents arrived with their wardrobes shaped by naive conceptions of their chosen professions, but quickly absorbed socializing messages from their school settings and professors."133

Moreover, while nearly all of the observed students exhibited "identity dissonance," that is, "the disconcerting experience of conflict between

${ }^{127} \mathrm{Id}$. at 27 .

${ }^{128} \mathrm{Id}$.

${ }^{129}$ Id. at 56-57.

${ }^{130}$ See generally Yang Costello, supra note 10.

${ }^{131}$ Id. at 139. Note that Costello points out that each of us possesses "multiple identities - be those of gender, race and ethnicity, and religion; class identities, sexual identities, political identities, familial identities, and so forth." Id. at 139.

132

${ }^{133}$ Id. at 143 . 
irreconcilable aspects of their self-concepts,"134 Costello observed "gendered and raced trends" in students' behavior. ${ }^{135}$ Her findings offer some additional support for the critiques of Stanchi and others, ${ }^{136}$ suggesting that those who do not selfidentify with the traditional image of the lawyer feel torn between their personal and professional identities. ${ }^{137}$ Costello's findings thus suggest that if legal writing education sends the message that lawyers are impatient, aggressive, and formalistic, we might expect some students in legal writing courses to struggle to with abandoning their prior identities in favor of those traits.

${ }^{134} \mathrm{Id}$. at 140 .

135 See Yang Costello, supra note 10. For example, at the law school, a white male student from an upper-middle-class background "relaxed into his new setting" quickly, leaving his long khaki slacks and long-sleeved button-down shirt for khaki shorts and a plain knit polo. Id. at 144. A white female student, in contrast, arrived at school "wearing a rather dramatic business outfit," and quickly "dressed herself down" to plain khaki pants and simple shifts, nothing feminine-looking. Id. at 145. The experience of an African-American female student was more complex. She arrived at school looking "businesslike, but in a dramatic, feminine, and ethnically marked way," wearing a brightly colored dress and matching jacket," braided hair, and jewelry that included African animal charms. Id. at 146. Soon, this student straightened and cut her hair into a simple blunt cut, and began wearing more delicate jewelry. She did not, however, change her style of clothing, and Costello theorized that the reason is that "a female law student of African descent is caught in a double bind: penalized professionally for her gender when she appears feminine, but penalized due to her race when she does not." Id.

${ }^{136}$ Some feminists, for example, have argued that legal education works to exclude women. For instance, in Becoming Gentlemen: Women's Experiences at One Ivy League Law School, Lani Guinier, Ann Bartow, and three other women presented their study of grades, survey data, written narratives, and interviews, demonstrating "that men outperform[ed] men at the University of Pennsylvania Law School," during the period of the study; and suggesting that women felt excluded from both the formal and informal education environments of the law school, and experienced adverse psychological effects and reduced employment opportunities as a result. Lani Guinier ET AL., supra note 8, at 6. The article's description of the characteristics students felt forced to emulate echos to some extent the image of the law-trained reader in legal writing textbooks:

Second only to the skills of "objectivity, students report that over time they have learned to stop caring about others and have become more conservative. Some men indicate that they have grown more aggressive and abrasive over their three years in law school; some women see themselves as more "humble" and "nitpicking." Id. at 51.

${ }^{137}$ Costello emphasizes that negative identity dissonance occurs in "individuals who prefer their personal identity to the conflicting professional identity," while those who "prefer their fledgling professional identities" experience identity dissonance in a positive way, "as if they are "finding themselves' at professional school." Id. at 152. 
In summary, recognizing that our students are in the midst of creating, or recreating, their own identities, legal writing teachers should not lightly throw out any generalizations about "what lawyers are like." In particular, we should not suggest to our students that these over-generalized traits of impatience, aggression, and formalism are necessary to success after law school.

\section{Avoiding Over-Generalizations About the Law-Trained Reader Improves Legal Writing Education.}

If legal writing textbooks and legal writing teachers stopped inviting students to imagine the audience for their writing as extraordinarily impatient, aggressive critics, red pens and format guides in hand, what instead should they say about law-trained readers? More critical, careful, reflective methods would better assist students in learning to grapple with the complex audiences and purposes for their writing.

As we develop better methods to help students imagine and write for the audience for their writing, legal writing professors might take inspiration from Getman's Voices, ${ }^{138}$ and seek to welcome the "human voice" in the law. As they stand, legal writing textbooks do not seem much to welcome or include the human voice. In a related vein, writing an essay for a symposium on narrative in legal writing, ${ }^{139}$ James R. Elkins has observed that "[w]ith the exclusive focus on technique, form, and structure in legal writing texts one experiences an eerie absence of the soul of the writing enterprise - a person who writes." ${ }^{240} \mathrm{He}$ wonders and worries specifically about the "lifeless instruction manual" at the base of many legal writing courses, the legal writing textbook:

One wonders how, in the enormity of structure and process, legal writing texts might affect the novice legal writer. How can one learn to write, to experience legal writing first-hand, to know struggle, failure, and the wonder of words and rules of law made into argument, when the task(s) of writing are provoked by and connected to a life-less instruction manual? (The most traditional of law school case books are filled with cases, and in turn, with people who have stories to tell, even if these stories have been

\footnotetext{
${ }^{138}$ See Getman, supra note 115.

${ }^{139}$ Elkins, supra note 10.

${ }^{140} I d$. at 107.
} 
severely "edited" by law.) What kind of invitation do legal writing texts extend to a student, or to any one of us, concerned that law be a humanistic and liberal art?

Reading these texts, I experienced a strong desire to flee, to find a place, any place where I could think about writing and learn the writing of legal argument free of these soulless texts. In this momentary feeling of being outsized, alone, and wishing to be elsewhere, I suspect a forewarning of the ways in which we isolate and disempower students who seek (in the most hopeful fashion) to learn the skills of writing associated with lawyering. Where does the legal writing text leave a solitary law student to stand, to learn, to think, to dream? ${ }^{141}$

Instruction in generalities about the specific (and mostly negative) personality traits of successful lawyers, and instruction in a specific formulaic method for writing each sentence and paragraph of the briefs and legal memoranda, probably gives some students Elkins" "desire to flee" to some other arena, a place that includes a place for the soul, for the human voice, in legal writing.

More recently, Andrea McCardle has echoed some of Elkins (and Stanchi's) concerns about alienation in legal writing and other skills education, "argu[ing] that all entering law students (and most novice lawyers) are outsiders to professional legal culture and its discourse. . . . [First-year law students] frequently express their frustration and lack of confidence, and they worry that they have lost touch with the sources of originality and creativity that once animated their writing." "142 Perhaps McCardle's most powerful insight is that,

as professional writers, lawyers always need to be conscious of the words they choose, and that creative choice is possible, and necessary, based on context, audience, and purpose. The

${ }^{141} I d$. at 108 (footnotes and citations omitted).

${ }^{142}$ McCardle, supra note 8, at 503-04. 
language of law should reflect the humanity and the serviceoriented goals of the legal profession.... ${ }^{143}$

Thus, McCardle questions whether perceived conflicts between the human voice and the professional voice appropriate to legal writing need necessarily result in muting the human voice. She challenges law teachers, law students, and lawyers, to take head on the difficult task of "understanding and renaming [legal] language" in our own words, thereby transforming ourselves "from being outsiders to self-reflective insiders of this professional discourse community."

Many of McCardle's suggestions for how to transform ourselves into "selfreflective insiders" would work well help engage first-year students in a more sophisticated discussion of the law-trained audience. For example, legal writing teachers might engage students in critical reading of judicial writing, considering "matters of style or voice," as well as "distinctive decision making approaches" connected to those styles and voices. ${ }^{145}$ We might consider assigning students, as McCardle suggests, "close, rhetorical reading of specimens of writing produced for professional legal contexts," such as Supreme Court briefs, ${ }^{146}$ or "reflective[] or imaginative[] [writing] about legal subjects outside of a practice-based context" as a "promising approach to cultivating individuality."

${ }^{143}$ Id. at 538 .

${ }^{144}$ Id. In a similar vein, see generally Kathryn Stanchi, Feminist Legal Writing, 39 SAN DiEGo L. REV. 387 (2002).

${ }^{145} I d$. at 506-07 (discussing voice in judicial opinions, and Richard Posner's typology of judicial writing styles in Richard Posner, Judges' Writing Styles (and Do They Matter)?, 62 U. CHI. L. ReV. 1421, 1429-32 (1995)).

${ }^{146}$ McCardle, supra note 8, at 514-16.

${ }^{147} I d$. at 520. McCardle notes with approval the approaches of Mark Weisberg, who in his "Legal Imagination" course "require[es] students to write a series of essays that address various social experiences and exclusions implicating the legal system"; and Derrick Bell, who in Constitutional Conflicts has required students to "write, among other things, 'op-ed' pieces about the constitutional doctrine they are learning." Id. at 521-22, note 74 (citing Mark Weisberg, Epilogue: When (Law) Students Write, 27 Legal Stud. F. 421 (2003) and Derrick Bell, Constitutional Conflicts: the Perils and Rewards of Pioneering in the Law School Classroom, 21 SEATtLE U. L. REV. 1039, 1047 (1998)). She also references James R. Elkins' use of "a semester-long journalwriting option in a course exploring the role of the lawyer and professional legal culture." McCardle, supra note 8, at 522, note 83 (citing James R. Elkins, Writing Our Lives: Making Introspective Writing a Part of Legal Education, 29 WiLlAMETTE L. REV. 45 (1993)). 
McCardle points out that, for instance, having novice legal writers read Ruthann Robson's Notes from a Difficult Case (in which Robson writes of her battle with medical problems and the exacerbation of those problems by medical malpractice, in legal, professional, and personal voices), ${ }^{148}$ "would be meaningful ... . [in that] Robson's honesty in registering her frustration with the formal terms of law and medicine, which are neither graceful, supple, nor humane, and her willingness to translate those terms into language that is more resonant and resilient.",149

Legal writing teachers might also take up Stanchi's proposal, that more critical legal scholarship should be introduced in the first year curriculum, and in the legal writing classroom. The wealth of scholarship on the subject of narrative in legal discourse offers food for thought, too. ${ }^{150}$

In fact, when not discussing the audience, many legal writing textbooks already acknowledge the importance of recognizing multiple influences on a given situation in the law. For instance, Edwards' textbook discusses the common student pitfall of "failing to realize the diverse possible interpretations of the facts." 151 Edwards notes that "[m]any writers new to law fall into the trap of assuming the infallibility of the inferences that someone else ... has drawn from the facts," and failing to "think independently and realistically." "152 They may also have trouble "imagining multiple interpretations simultaneously."153

In a similar vein, legal writing teachers might consider David R. Papke's suggestion that, if legal education engaged law students in reading and analyzing appellate opinions as a sort genre literature, one beneficial effect might be that "[1]aw school graduates might learn to tell better stories on behalf of clients, draft fairer imagined worlds in legislatures, and shape more thoughtful master narratives from the bench." David Ray Papke, Appreciating the Storytelling of Appellate Opinions, 220 (in David Ray PAPKe, ed., NARRATIVE AND the Legal Discourse (1991)).

${ }^{148}$ See Ruthann Robson, Notes from a Difficult Case, In FaCt: The Best of Creative Nonfiction 226 (Lee Gutkind, ed., 2005) (cited in McCardle, supra note 8, at 533, note 112).

149 McCardle, supra note 8, at 534. McCardle acknowledges that engaging students in such sophisticated critical thought about the legal language they are still in the midst of learning may be challenging, but argues that such work is just the thing that may "help[] to illuminate how legal writers can bridge the space between a socialized professional voice, individuality, and interpersonal client-attorney communication." Id. at 534-36.

${ }^{150}$ See, e.g., DAVid RAY PAPKe, ED., NARRATIVE AND the Legal DiscourSe (1991), and 20 (1\&2) LEGAL STUD. F. 95 (1996).

${ }^{151}$ EDWARDS, supra note 16, at 104.

${ }^{152} I d$.

${ }^{153} I d$. 
Edwards suggests that "each year of law practice will improve your ability to see diverse interpretations of a set of facts."

Applying a similarly thoughtful, reflective approach to discussions of the audience for legal writing would better help students grapple with the difficult task of negotiating between their own voices and the audience for their writings.

Some legal writing teachers may resist the idea of adding assignments or approaches to the first-year legal writing education, especially since, as Stanchi points out, "[t]he goals, methodologies, and teaching framework of both the process and social views of legal writing teach law students how to communicate the language of the law effectively," 155 and some legal writing professors already feel they "barely have the time and course hours to teach conventional legal analysis, much less critical theory, positionality method or 'meticulous analysis." "156 Or, one might add, narrative theory, reflective writing, and longer, more complicated discussions about the law-trained reader.

Whether legal writing teachers approach the task consciously or not, however, the fact is that legal writing courses inevitably are about more than simply the technical matters, the vocabulary and manner of legal communication. They are about "what lawyers are like." We should stop offering half-truths and generalizations about the "law-trained reader," and instead acknowledge the more difficult reality, “the 'situated legal writer' who must operate with a recognition of institutional contexts and practices that make law a highly complex professional discourse community.",157

\section{Conclusion}

In her book presenting her findings about students' identity dissonance in more detail, Costello ends with a section describing "Strategies for Reducing Identity Dissonance," 158 arguing that "[t]he simplest and most important step is to

\footnotetext{
${ }^{154} \mathrm{Id}$. at 105 .

${ }^{155}$ Stanchi, supra note 8 , at 16.

${ }^{156} I d$.

${ }^{157}$ Rideout and Ramsfield, supra note 2, at 98-99.

158 Carrie Yang Costello, Professional Identity Crisis: Race, Class, Gender, and Success at Professional Schools 230 (2005).
} 
acknowledge that the problem of identity dissonance exists."159 Legal writing instructors have the opportunity to acknowledge the phenomenon of identity dissonance when they engage students in thinking about the characteristics of the law-trained reader. If instead legal writing teachers offer over-generalizations about lawyers' impatience, aggression, and formalism, without comment or critique, we undermine our own credibility and teaching, and we send the message that students should resolve perceived conflicts between their personal and professional identity by abandoning personal identity in favor of the generalizations we articulate. At the very least, legal writing education should stop offering such overgeneralizations about what lawyers are like, and should welcome more reflective, human discussions that might fill the vacuum left by that silence.

${ }^{159}$ Id. at 231. 